\author{
by Svetlana Lukishova', Anatoly Masalov ${ }^{2}$ and Victor Zadkov ${ }^{3}$ \\ ${ }^{1}$ Institute of Optics, Univ. of Rochester, USA - ${ }^{2}$ Lebedev Physical Institute, Russia \\ ${ }^{3}$ Institute of Spectroscopy, Russian Academy of Sciences, Russia - DOI: https://doi.org/10.1051/epn/2019405
}

\title{
A lesson from the history of scientific discovery of measuring the pressure of light
}

d n 2012, a memorial plaque was unveiled by the American Physical Society at Dartmouth College (Hannover, USA), which tells us that "At this site, ... from 1900-1903 E.F. Nichols and G.F. Hull performed the first precise measurement of the radiation pressure of light on a macroscopic body, as predicted by J.C.Maxwell in 1873. The Nichols-Hull experiment provided convincing evidence for the pressure of light, and the transfer of momentum between light and matter, a phenomenon which has enabled critical developments in a wide range of fields from atomic physics to biology to astrophysics."

How did it happen then that the priority of the Russian scientist P.N. Lebedev in measuring the pressure of light was ignored? Here is our opinion on that.

Experiments on detection of light pressure on solids were undertaken at the beginning of the last century by P.N. Lebedev in Moscow, and by E.F.Nichols and G.F.Hull $(\mathrm{N} \& \mathrm{H})$ at Dartmouth College (Hanover, USA). These scientists worked independently of each other. The first message of success came from P.N. Lebedev, who made a report on his measurements at the Congrès International de Physique in Paris in 1900. His report was published in the proceedings of the conference [1] in sufficient detail (7 pages). These results were also published in Russian in an article [2]. A more complete description of the experiments was published in 1901 [3], and in Russian in [4]. An English translation of paper [4] is presented in the book [5] (Chapter 12). N\&H found out about the publication of P.N. Lebedev [1], and in December 1901 E.F. Nichols wrote a letter to P. Lebedev with a request for a reprint of Lebedev's paper. N\&H published their own results on measuring the light pressure in 1901 as a preliminary report [6] and in a complete form in 1903 [7]. The main conclusion which was deduced by $\mathrm{N} \& \mathrm{H}$ from their measurements [7] does not differ from the conclusion of P.Lebedev in Annalen der Physik [3]:"Thus, the Maxwell-Bartoli theory confirmed quantitatively within the measurement error" with the distinction that this finding was published two years later. A particular result claimed by $\mathrm{N} \& \mathrm{H}$ was the value of the measurement error 1\%, while P.Lebedev evaluated the accuracy of his measurements as $20 \%$. This difference became the reason for considering the research of $\mathrm{N} \& \mathrm{H}$ as the first high-precision light pressure measurement (see the text on the memorial plaque).

The N\&H statement about the $1 \%$ accuracy of the coincidence between the measurement results and the estimate of light pressure according to Maxwell's theory was actually wrong.

First, to compare the experimental data on the pressure of light with the expected value, it is necessary to know the power of the acting light beam in absolute units. Until now, after a century of optical experiments, the absolute measurement of light power remains a delicate task. Calibration accuracy is usually only a few \%; the most accurate meters claim $1 \%$ calibration accuracy. At the time of $\mathrm{N} \& \mathrm{H}$ it was impossible to imagine that the calibration of their source was performed with $1 \%$ accuracy. The only thing that can be agreed upon regarding the measurements of $\mathrm{N} \& \mathrm{H}$ is the $1 \%$ reproducibility of measurements. But this is not at all what can be called a $1 \%$ coincidence with the theory.

Then, a confirmation of doubts about $1 \%$ measurement precision can be found in a paper by M.Bell and S.E. Green [8], published in 1933. During their own measurements, they showed specific inaccuracies in the calculations of light pressure forces presented in N\&H's paper [7]. Correction of these factors, made by Bell and Green, led to a discrepancy of $10 \%$ between experimental data and the theory of Maxwell-Bartoli. In the Abstract to the paper [8] they wrote: "Although their (Nichols 
[ Letter to the Editors]

and Hull's) work, carried out at a gas pressure of $16 \mathrm{~mm}$ of mercury, has been widely quoted as conclusively establishing, to within about 1 per cent, the numerical equivalence between the pressure and energy-density of radiation, it is found that their results, when correctly evaluated, show a divergence between these quantities of some 10 per cent. Hence Nichols' and Hull's investigation cannot be regarded as furnishing a quantitative experimental verification of the equality relationship deducible from theory." In a joint paper [9] Hull did also admit an error of some $10 \%$ (see also Chapter 13 in [5]).

This clearly proves that the Russian scientist was first to measure the pressure of light and that $\mathrm{N} \& \mathrm{H}$ independently confirmed his experiment with roughly the same accuracy.

Finally, the question arises why the APS decided to rewrite the history of scientific achievements?

\section{References}

[1] P. Lebedew, "Les forces de Maxwell-Bartoli dues à la pression de la lumière" Rapports présentés au Congrès International de Physique 2, 133 (1900).

[2] P. Lebedev, Journal of the Russian Physico-Chemical Society (Ж.Р.Ф.Х.О., ч.физ.), 32(1), 211 (1900); in Russian.

[3] P. Lebedew, Annalen Der Physik 311 (11), 433 (1901).

[4] P.N. Lebedev, Journal of the Russian Physico-Chemical Society (Ж.Р.Ф.Х.О., ч. физ.) 33(1), 53 (1901); in Russian.

[5] Quantum Photonics: Pioneering Advances and Emerging Applications. Eds. R.W.Boyd, S.G. Lukishova, V.N.Zadkov. Springer 2019.

[6] E.F. Nichols, G.F.Hull, Phys. Rev. Series / 13, 307 (1901).

[7] E.F. Nichols, G.F.Hull, Phys. Rev. Series / 17, 26 (1903). Ibid. 17, 91 (1903)

[8] M. Bell, S.E.Green, Proc. Phys. Soc. 45, 320 (1933).

[9] G.F. Hull, M. Bell, S.E. Green, Proceedings of the Physical Society 46 № 256, 589 (1934).
TH Y R $\triangle \mathrm{CONT}$

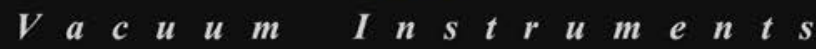
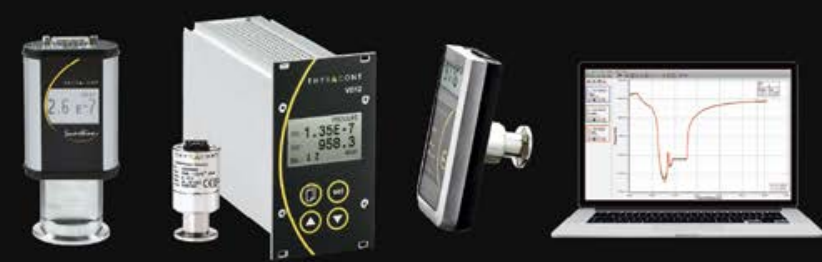

Meet us at the

Vacuum Expo 2019

Booth W25
Thyracont develops and manufactures vacuum gauges in the measurement range of 1400 - 5e-10 mbar.

We offer a wide range of measuring principles such as:

Piezo, Pirani, capacitive, cold cathode and hot cathode.

Contact us in order to learn more about our digital Smartline ${ }^{\mathrm{TM}}$ vacuum transducers,

VD8 compact vacuum meters and Analogline analog vacuum transducers.
INTELLIGENT VACUUM MEASUREMENT SINCE 1970 